\title{
Epicardial infrared ablation to create a linear conduction block on a beating right atrium
}

Hiroshi Kubota* (D), Hidehito Endo, Hikaru Ishii, Hiroshi Tsuchiya, Yusuke Inaba, Yu Takahashi

and Katsunari Terakawa

\begin{abstract}
Background: It is still difficult to create a secure linear conduction block on a beating heart from the epicardial side. To overcome this drawback we developed an infrared coagulator equipped with a cuboid light-guiding quartz rod. This study was designed to electrophysiologically confirm the efficacy of a new ablation probe using infrared energy in a clinical case.

Methods: The infrared light from a lamp is focused into the newly developed cuboid quartz rod, which has a rectangular distal exit-plane that allows $30 \mathrm{~mm} \times 10 \mathrm{~mm}$ linear photocoagulation. Two pairs of electrodes were attached to the right atrium of a patient who was undergoing surgery. Each pair of electrodes was placed $10 \mathrm{~mm}$ from an ablation line. The change in conduction time between the two pairs of electrodes was measured during ablation. The predicted conduction time delay ratio was 1.54 .
\end{abstract}

Results: The actual conduction time after ablation was 1.38-1.43 times longer than the pre-ablation conduction time. Conclusions: The infrared ablation using a newly developed cuboid probe made it possible to create a linear conduction block on the beating right atrial free wall clinically.

Keywords: Atrial fibrillation, Ablation, Coagulator, Energy source, Electrophysiology, Arrhythmia treatment, Infrared, Minimally invasive surgery, Maze procedure, Photocoagulation

\section{Background}

The newly developed infrared coagulator, named the "Kyo-Co (Photon incorporation, Saitama, Japan)", contains a reflector that focuses light from a tungsten-halogen lamp into a light-conducting $30 \mathrm{~mm} \times 10 \mathrm{~mm}$ cuboid quartz rod, and the light emerges as $35 \mathrm{~W} / \mathrm{cm}^{2}$ of near-infrared light energy (wavelength: $400 \mathrm{~nm}$ to approximately $1600 \mathrm{~nm}$; peak wavelength: $850 \mathrm{~nm}$ ). The distal exit-plane of the light-conducting rod has a rectangular plane surface $(30 \times 10 \mathrm{~mm})$ (Fig. 1).

\section{Methods}

In a preliminary experiment, the probe applied to a specimen of chicken muscle tissue, and the muscle tissue was ablated for a total of $28 \mathrm{~s}(4 \mathrm{~s} \times 5$ times at

\footnotetext{
* Correspondence: kub@ks.kyorin-u.ac.jp

Department of Cardiovascular Surgery, Kyorin University, 6-20-2, Shinkawa, Mitaka, Tokyo 181-8611, Japan
}

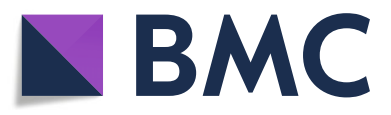

(c) The Author(s). 2018 Open Access This article is distributed under the terms of the Creative Commons Attribution 4.0 International License (http://creativecommons.org/licenses/by/4.0/), which permits unrestricted use, distribution, and

reproduction in any medium, provided you give appropriate credit to the original author(s) and the source, provide a link to the Creative Commons license, and indicate if changes were made. The Creative Commons Public Domain Dedication waiver (http://creativecommons.org/publicdomain/zero/1.0/) applies to the data made available in this article, unless otherwise stated.

$2 \mathrm{~s}$ intervals $)(n=5)$. Tissue temperature with time was measured with a thermometer Ti480 (Fluke Corporation, WA, U.S.A.). The maximum temperature of muscle tissue was measured. After ablation of the chicken muscle the depth of the lesion was measured macroscopically.

The maximum temperature of the chicken muscle was $97.9+2.1{ }^{\circ} \mathrm{C}$, and the depth of the lesion was $8.7+0.8 \mathrm{~mm}$ (Fig. 2).

\section{Clinical experience}

In 2014, the ethics committee of Kyorin University approved a clinical and epidemiologic study entitled, Surgical treatment of arrhythmias, infectious endocarditis, infected aortic aneurysms, and cardiac tumors with an infrared coagulator. Written consent was obtained from the patient.

We hypothesized that when a rectangular transmural lesion is created in the same shape as the exit plane of 


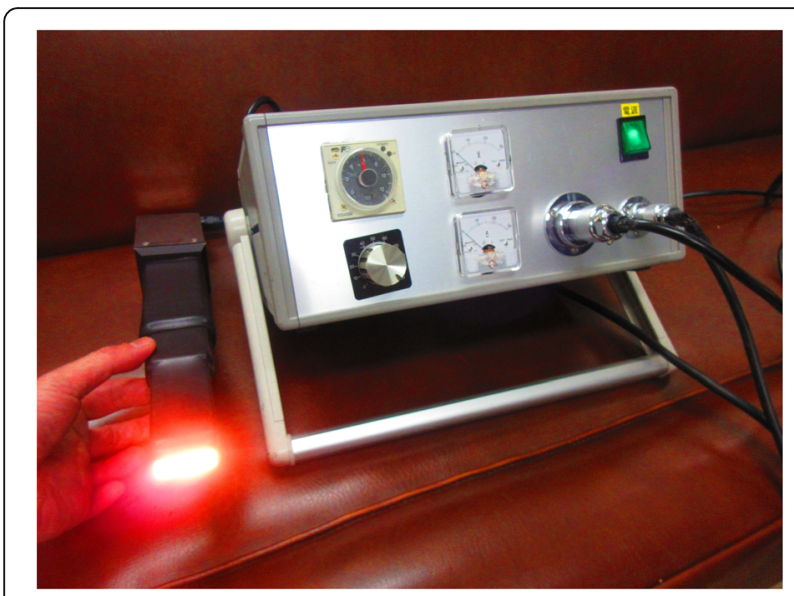

Fig. 1 Infrared coagulator "Kyo-co". The cuboid quartz rod exit plane has a rectangular $(30 \mathrm{~mm} \times 10 \mathrm{~mm}$ ) surface designed to enable creation of a linear lesion. Light from a tungsten-halogen lamp emerges as $35 \mathrm{~W} / \mathrm{cm}^{2}$ of near-infrared light energy (wavelength: 400 to approximately $1600 \mathrm{~nm}$; peak wavelength: $850 \mathrm{~nm}$ )

the cuboid quartz rod, the translesion conduction time would be prolonged. We predicted that the conduction time prolongation ratio (post-ablation conduction time/pre-ablation conduction time) would be directly proportional to the conduction distance prolongation ratio (post-ablation conduction distance/pre-ablation conduction distance). The predicted conduction prolongation ratio was $46.1 / 30.0 \mathrm{~mm}=1.54$ (Fig. 3). After obtaining written informed consent from the patient, in August 2016 mitral and tricuspid valve plasty and a maze procedure were performed on a 64-year-old man with infectious endocarditis, severe mitral regurgitation, moderate tricuspid regurgitation, and paroxysmal atrial fibrillation. After a median sternotomy, the pericardium was opened, and the epicardial atrial ablation and electrophysiological study were performed before commencing the cardiopulmonary bypass. Two pairs of alligator clip electrodes were attached to the right atrium $10 \mathrm{~mm}$ from the expected ablation line. The pair of electrodes attached on the dorsal side of the ablation line was used to pace the right atrium, and the pair of electrodes attached on the ventral side of the ablation line was used as sensing electrodes to record the atrial potential. The cuboid $30 \mathrm{~mm}$ long $10 \mathrm{~mm}$ wide quartz rod of the infrared coagulator was applied epicardially to create a linear lesion on the free wall of the beating right atrial free wall as part of the incision line of the maze procedure (Fig. 3). The total duration of each ablation was $28 \mathrm{~s}$ applied in a 5 series of $4.0 \mathrm{~s}$ each at $2.0 \mathrm{~s}$ intervals. The pacing rate was set to $90 \mathrm{bpm}$. An electrocardiogram (ECG) and atrial potentials were recorded with an HPM 4500 polygraph (Fukuda Denshi, Tokyo, Japan).

Because the atrial potential was biphasic in shape, conduction times were measured as the interval between stimulation (S) and each peak of the atrial potential (A1 and A2, Fig. 4), and plotted. After the experiment, a square specimen with a side length of $5 \mathrm{~mm}$ of coagulated right atrial wall was excised, stained with Masson trichrome, and examined microscopically.

\section{Results}

From 1st to 4th infrared application, both S-A1 conduction time and S-A2 conduction time were prolonged and incompletely reversed each time (Fig. 5).

After 4th infrared application, both S-A1 and S-A2 conduction time plateaued, and the 5th infrared application did not affect either conduction time.

S-A1 conduction time was prolonged from $7.2 \mathrm{~ms}$ to $10.3 \mathrm{~ms}$. The conduction prolongation ratio was $10.3 / 7.2=1.43$.

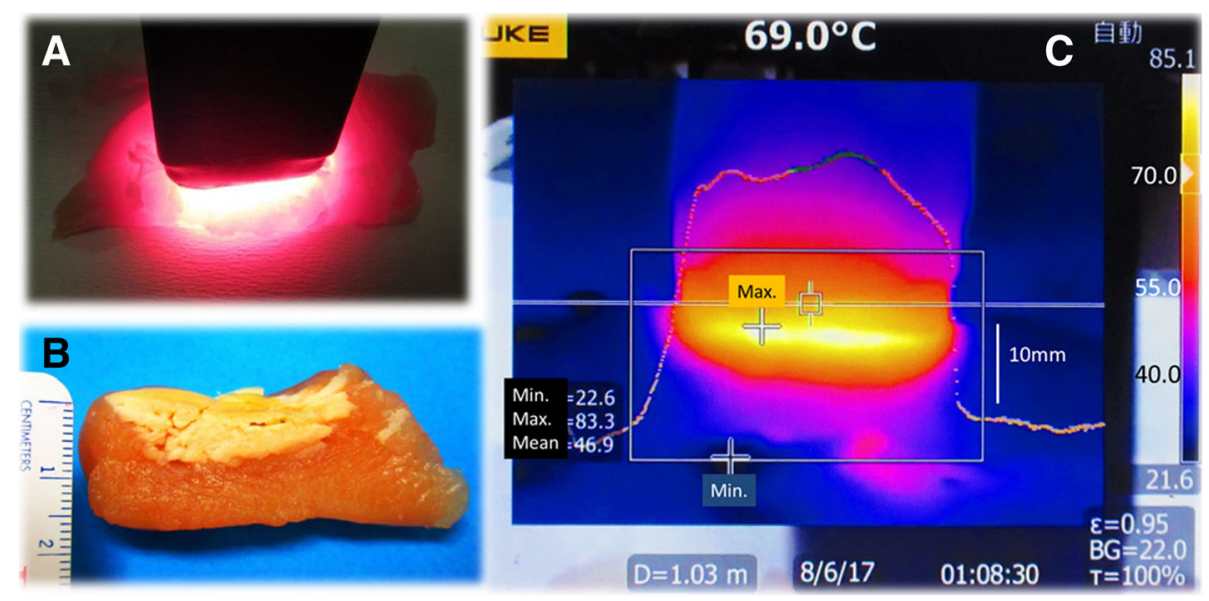

Fig. 2 Preliminary experiment on chicken muscle tissue. a The probe was pressed against the muscle tissue. $\mathbf{b}$ The mean depth of the lesion was $8.7+0.8 \mathrm{~mm}$. c The maximum temperature was $97.9+2.1^{\circ} \mathrm{C}$ 


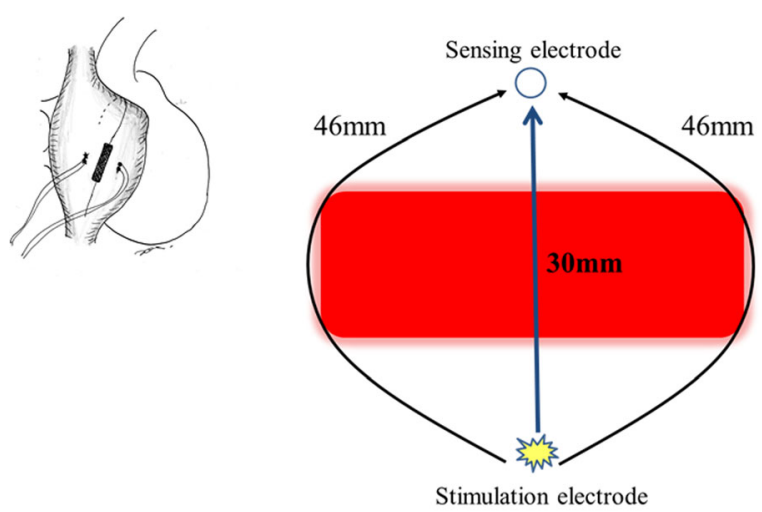

Hypothesis:

Conduction prolongation ratio $=46 / 30 \mathrm{~mm}=1.54$

Fig. 3 Prediction. Because the conduction distance prolongation ratio is directly proportional to the conduction time prolongation ratio, when a linear transmural lesion is created in the same shape as the rectangular exit plane, the conduction time prolongation ratio is predicted to be 1.54

S-A2 conduction time was prolonged from $8.6 \mathrm{~ms}$ to $11.9 \mathrm{~ms}$. The conduction prolongation ratio was $11.9 / 8.6=1.38$.

Histopathologic examination of the ablated right atrium showed preservation of both the endocardium and epicardium of the coagulated lesion (Fig. 6). Severely degenerated myocardium was observed from the epicardial side to mid-portion of the atrial wall. Swelling and hyperchromatosis of the nuclei, acidophilic change in the cytoplasm, and deformity of the myocardium were observed in the myocardium on the endocardial side.

\section{Discussion}

To realize the epicardial maze procedure, the major drawback is how to make the transmural lesion on the beating atrial free wall under the condition of existence of inner warm blood flow which weakens heating/cooling effect of the ablation device.

Nath et al. demonstrated that hyperthermia induced by radiofrequency energy causes significant changes in the electrophysiological properties of myocardiocytes, including membrane depolarization, reversible and irreversible loss of excitability, and abnormal automaticity, in an in vitro isolated guinea pig right ventricular papillary muscle

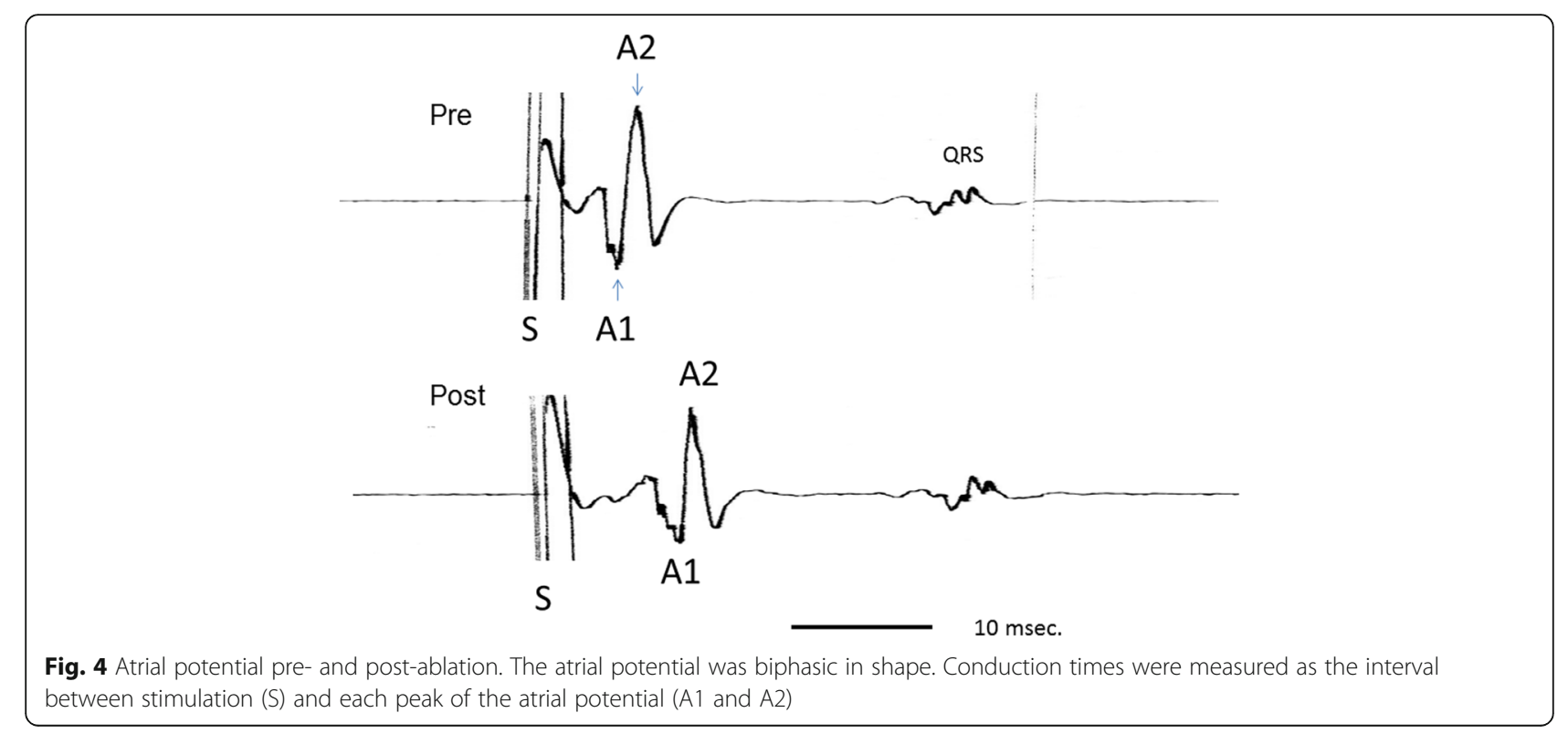




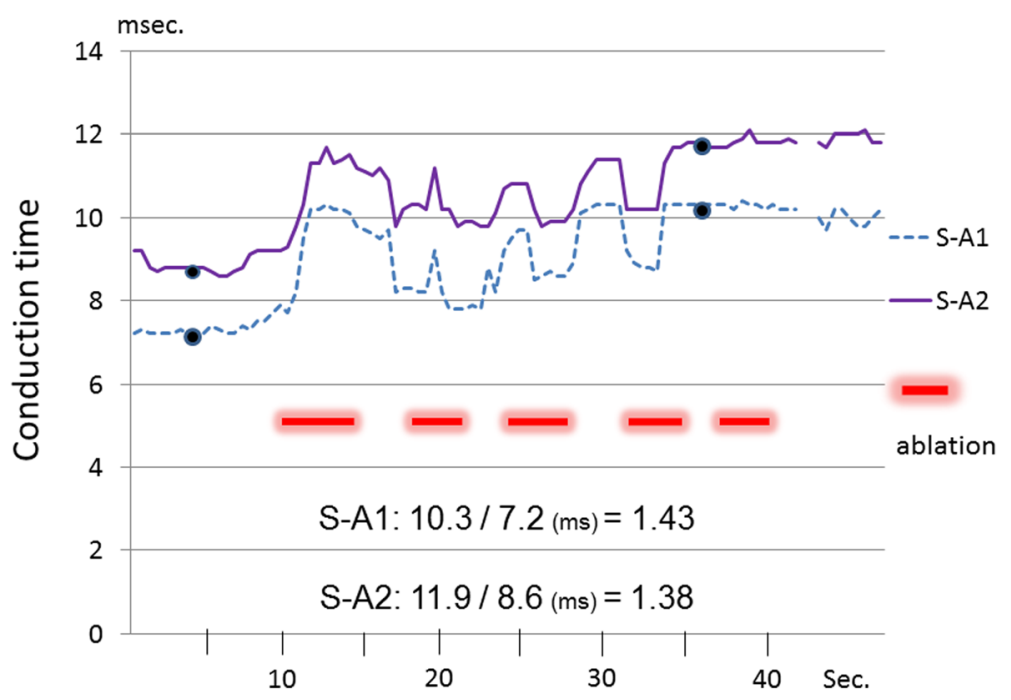

Fig. 5 Atrial potentials pre-ablation and post- ablation (S: stimulation). Biphasic atrial potentials were recorded (A1 and A2). Both S-A1 conduction time and S-A2 conduction time were prolonged after the $28 \mathrm{~s}$ of ablation, and the conduction prolongation ratios were 1.43 and 1.38 , respectively

model. They observed reversible loss of cellular excitability and tissue injury after exposure to temperatures in the $42.7{ }^{\circ} \mathrm{C}$ to $51.3{ }^{\circ} \mathrm{C}$ range (median, $48.0{ }^{\circ} \mathrm{C}$ ) for $60 \mathrm{~s}$ and irreversible loss of cellular excitability and tissue injury after exposure to temperatures $>50{ }^{\circ} \mathrm{C}$ for 60 seconds [1].
Bulava et al. assessed the efficacy of epicardially created lesions produced with bipolar radiofrequency (RF) energy in 70 patients who had persistent, longstanding atrial fibrillation [2] and reported achieving complete isolation of the posterior left atrial wall in only $22.9 \%$ of the patients. The success rates for creating conduction

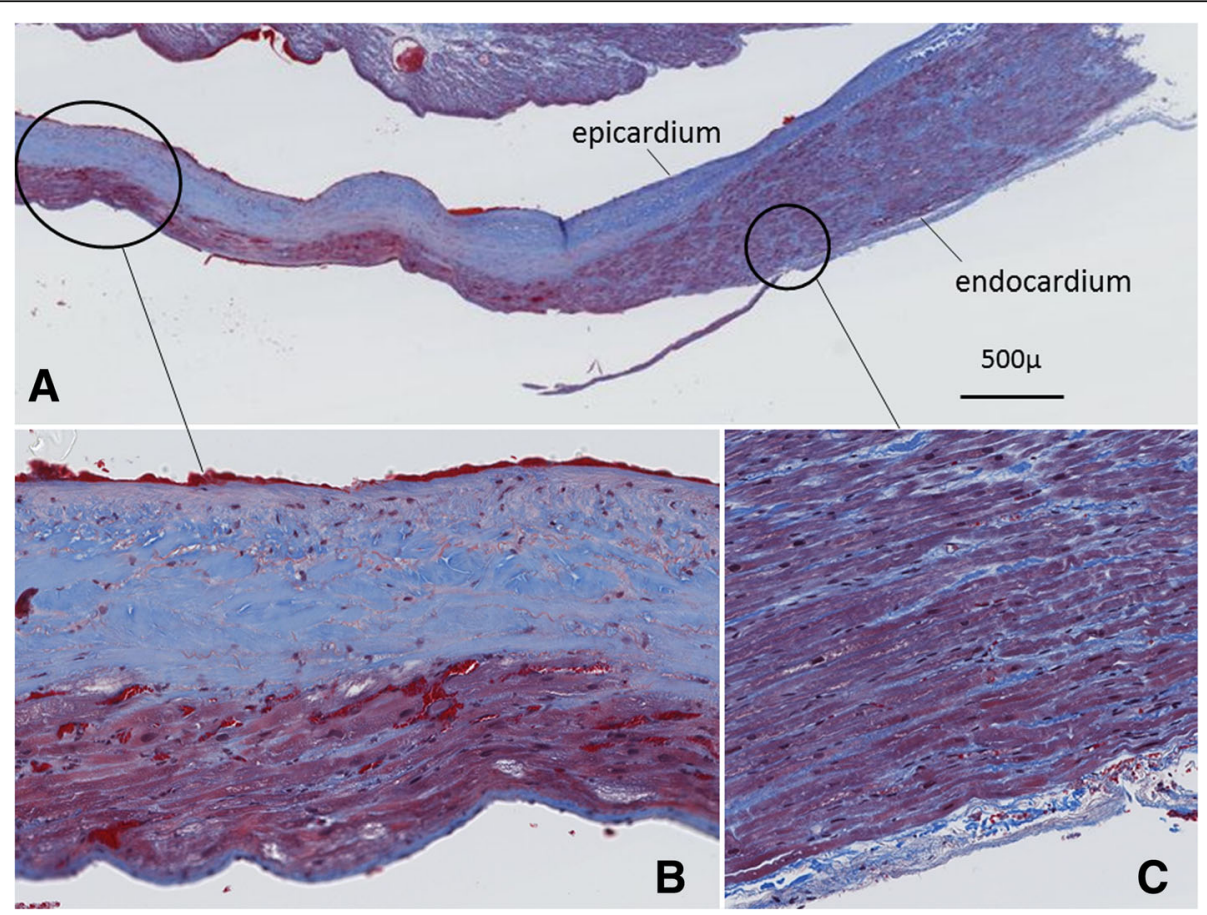

Fig. 6 Histopathologic changes in the ablated right atrium. a Histologic examination showed preservation of both the endocardium and epicardium of the coagulated lesion. Both the endocardium and the epicardium were intact. $\mathbf{b}$ Severely degenerated myocardium was observed from the epicardial side to the mid-portion of the atrial wall. The endocardial side showed swelling and hyperchromatosis of the nuclei, acidophilic change in the cytoplasm, and deformity of the myocardium. c Myocardium was intact at the endocardial side of the marginal legion 
block across the inferior pulmonary veins (PVs) and across the roof line connecting the two superior PVs were only 58.0 and $24.3 \%$, respectively. Right PVs were found to have been isolated in a significantly higher proportion of patients (91.4\%) than the left PVs (75.7\%) were. The low efficacy of epicardial RF ablations in creating a transmural irreversible electrophysiological block, especially on the "unclampable free wall" of the atrium, represent that heat sinking effect of the inner blood flow that weaken the thermal effect of the RF.

We previously reported the fundamental results of using an infrared coagulator in animal models [3-5]. The results of the series of experiments in animal models revealed that an infrared coagulator enables creation of a transmural lesion on the canine beating right ventricle to a maximum depth of $10.3 \mathrm{~mm}$, a conduction block on an arrested heart, and a conduction block on a beating right atrium. A successful epicardial maze procedure and successful electrical isolation of the right atrial appendage with an infrared coagulator and concomitant on-pump beating coronary artery bypass grafting have been reported in a clinical case [6,7].

A cuboid probe was newly developed to create a linear lesion and conduction block on the atrial free wall. To demonstrate the conduction block on the beating heart, encircled lesions e.g. the both atrial appendage, PV cuffs, or box lesion are easy because the ineffective overdrive pacing from inside the lesion can prove the exit block. By contrast, it is difficult to demonstrate a conduction block on a beating atrial free wall. Intraoperative epicardial mapping with multi-electrodes is in common use, but it requires a large-scaled mapping system. Furthermore, because the multi-electrodes are just placed on the epicardium, not attached to it, they slip, and it is difficult to be estimate the exact electrical conduction time. A polygraph with two channels was used in our patient, and it was possible to measure the exact conduction time in every heart beats. We hypothesized that an increase in the translesion stimulus-excitation delay indicates a continuous, transmural, linear lesion, and that the translesion stimulus-excitation delay is directly proportional to path length in the viable tissue around the lesion. Himel et al. demonstrated that complete lesions with RF in rabbit hearts increase translesion stimulus-excitation delay, whereas incomplete lesions do not increase the delay [8]. As far as we investigated, there is no report that proved the stimulus excitation delay on the ablated epicardial atrial free wall in a clinical case. The right atrial free wall was selected for examination. It is easy to apply the cuboid-shaped probe to the right atrial free wall, and it was thought that it would be more difficult to make a transmural lesion in the right atrium than in the left atrium, because the right atrium has a complicated inner structure due to its thick trabecular muscle.
In our patient the myocardium was ablated intermittently at 2-s intervals. Intermittent ablations are more effective than long continuous ablations, because the intervals prevent rapid temperature rise, and prevent to make charring that blocks the photo-energy radiation deep inside the myocardium.

The actual conduction prolongation ratios in the present study were smaller than the predicted ratios, and the main reason for the smaller ratios is thought to be that it was difficult to determine the exact distance between the ablation line and alligator clip electrodes. To determine the more acculate distance, using small bipolar needle electrodes is better. Marginal non-transmural lesions and atrial tissue shrinkage are considered to be other factors that affect conduction time; both factors may shorten the conduction distance and reduce the prolongation ratio.

Pathological examination of the tissue obtained from our patient confirmed the presence of transmural degeneration, however, it was not homogeneous. It may represent the heat sinking effect of the inner blood flow. Considering the result of the presented electrophysiologocal study, there may be a discrepancy between the histopathological transmurality of the lesion and its electrophysiological transmurality. The histopathological change may not exactly represent the electrophysiological change but instead underestimate it by overlooking the pathologically normal but electrophysiologically remodeled lesion of the myocardium. Chronic reversibility of the prolonged conduction time was not investigated in this study. However, in a previous animal study we verified hemosiderin deposition, macrophage invasion, increased capillary vessels, and increased juvenile elastic fibers in the right atrial free wall 3 months after ablation. The myocardium did not revive, the endocardium became thickened, and elastic fibers appeared.

Theoretically, same as RF, this new technology can be applied not only to the atrium but also to the ventricle. Modifying the shape and flexibility of the probe may enable safe and effective minimally invasive endoscopic ablation to create a box lesion on the beating left atrium and to treat ventricular tachycardia based on the same tissue photocoagulation principle as described above.

\section{Conclusions}

The newly developed cuboid probe of the Kyo-co infrared coagulator may have the potential to serve as a reliable device for performing the epicardial maze procedure on the beating atrial free wall clinically.

\section{Abbreviations}

ECG: Electrocardiogram; RF: Radiofrequency

\section{Acknowledgments}

The authors wish to thank Ms. Yuki Matsumoto for her assistance with the data analysis in this study. 


\section{Funding}

This study was supported by funding from the "Leading-edge Industry

Design Project, Medical Innovation, Saitama Prefecture, Japan, 2016."

\section{Availability of data and materials}

The datasets used and/or analyses during the current study are available from the corresponding author on reasonable request.

\section{Authors' contributions}

HK designed and drafted the MS. HE, HI, HT, and YI drafted and revised the MS. YT, and KT analyzed and interpreted the measured data. All authors have approved to the submission of the MS

\section{Ethics approval and consent to participate}

In 2014, the ethics committee of Kyorin University approved a clinical and epidemiologic study entitled, Surgical treatment of arrhythmias, infectious endocarditis, infected aortic aneurysms, and cardiac tumors with an infrared coagulator. Written consent was obtained from the patient.

\section{Consent for publication}

Written consent to be published was obtained from the patient.

\section{Competing interests}

The authors declare that they have no competing interests.

\section{Publisher's Note}

Springer Nature remains neutral with regard to jurisdictional claims in published maps and institutional affiliations.

Received: 27 April 2018 Accepted: 5 November 2018

Published online: 16 November 2018

\section{References}

1. Nath S, Lynch C III, Whayne JG, Haines DE. Cellular electrophysiological effects of hyperthermia on isolated Guinea pig papillary muscle. Implications for catheter ablation. Circulation. 1993;88:1826-31.

2. Bulava A, Mokracek A, Kurfirst V. Delayed electroanatomic mapping after surgical ablation for persistent atrial fibrillation. Ann Thorac Surg. 2017, 104(6):2024-9.

3. Kubota H, Furuse A, Takeshita M, Kotsuka Y, Takamoto S. Atrial ablation with an IRK-151 infrared coagulator. Ann Thorac Surg. 1998;66:95-100.

4. Kubota H, Takamoto S, Takeshita M, Miyaji K, Kotsuka Y, Furuse A. Atria ablation using an IRK-151 infrared coagulator in canine model. J Cardiovasc Surg. 2000:41:835-47.

5. Kubota H, Kenichi S, Takamoto S, et al. Clinical result of epicardial pulmonary vein isolation (LAVIE) by cryoablation as concomitant cardiac operation and clinical application of new device (KIRC-119 infrared coagulator) to treat atrial fibrillation. In: Choi II, editor. Atrial fibrillation-basic research and clinical applications. Croatia: Intech; 2011. p. 267-90.

6. Kubota $\mathrm{H}$, Takamoto S, Furuse A, et al. Epicardial maze procedure on the beating heart with an infrared coagulator. Ann Thorac Surg. 2005;80:1081-6.

7. Kubota H, Sudo K, Takamoto S, et al. Epicardial electrical isolation of the right atrial appendage on the beating heart with an infrared coagulator. Ann Thorac Surg. 2009;87:1592-5.

8. Himel IV, Dumas HJ III, Kiser AC, Knisley SB. Translesion stimulus-excitation delay indicates quality of linear lesions produced by radiofrequency ablation in rabbit hearts. Physiol Meas. 2007;28:611-23.

Ready to submit your research? Choose BMC and benefit from:
- fast, convenient online submission
- thorough peer review by experienced researchers in your field
- rapid publication on acceptance
- support for research data, including large and complex data types
- gold Open Access which fosters wider collaboration and increased citations
- maximum visibility for your research: over 100M website views per year
At BMC, research is always in progress.
Learn more biomedcentral.com/submissions

